Research Article

\title{
Evaluating the Fatigue Resistance of the Innovative Modified-Reinforced Composite Asphalt Mixture
}

\author{
Gholamali Shafabakhsh (D), Mahdi Akbari $(\mathbb{D}$, and Hossein Bahrami $(\mathbb{D}$ \\ Faculty of Civil Engineering, Semnan University, Semnan, Iran \\ Correspondence should be addressed to Gholamali Shafabakhsh; ghshafabakhsh@semnan.ac.ir
}

Received 19 August 2020; Revised 22 November 2020; Accepted 26 November 2020; Published 8 December 2020

Academic Editor: Hui Yao

Copyright ( $\odot 2020$ Gholamali Shafabakhsh et al. This is an open access article distributed under the Creative Commons Attribution License, which permits unrestricted use, distribution, and reproduction in any medium, provided the original work is properly cited.

\begin{abstract}
Fatigue failure is regarded as one of the most common failures in the road pavement and necessitates spending huge cost annually to maintain the road. Asphalt binder modification and asphalt mixture reinforcement are among the commonly used methods to increase the pavement resistance to a failure caused by fatigue. By proposing a modified-reinforced composite hot mix asphalt (MRC-HMA), the present study aimed to examine the fatigue life of this mixture with one of the most traditional methods (i.e., four-point bending beam fatigue test) and compare it at constant strain conditions and the strain levels of 500, 700, and $900 \mu \varepsilon$ and a temperature of $20 \pm 0.8^{\circ} \mathrm{C}$ to that of the other three specimens, including control specimens, geogrid-reinforced (GR-HMA) specimens, and nanosilica-modified (NSM-HMA) specimens with 5\% nanosilica. In all experiments, the condition to reach the failure stage was assumed equivalent to a $50 \%$ reduction in the stiffness coefficient in each load repetition, and the load was applied semisinusoidal at a frequency of $10 \mathrm{~Hz}$ without rest. The results showed that the MRC-HMA mixture improved the fatigue life at the strain level of $500 \mu \mathrm{s}$ by about 701, 172.5, and $156.4 \%$ compared to the control, NSM-HMA, and GR-HMA specimens, respectively. Based on the results, the use of GR-HMA specimens has almost the same results as NSM-HMA ones, but the use of the MRC-HMA mixture can significantly increase the fatigue life of MRC-HMA in all three levels of strain compared to all specimens studied in the present study. Thus, the introduced mixture can be a proper choice for pavements with heavy or light (with a large amount) traffic loads, which usually have a vast adverse effect on the fatigue behaviour of asphalt mixtures.
\end{abstract}

\section{Introduction}

Traffic loading and environmental issues are the most important factors causing damage in the asphalt pavement which could contribute to accidents [1,2]. Traffic loading results in damages (e.g., rutting and fatigue cracks), and environmental issues such as temperature are the main factors of low-temperature cracks. Depending on some factors (e.g., load limit, contact area, temperature, pavement roughness, and thickness), traffic loading can lead to tensile, compressive, and shearing stresses or combination of them in different parts of the pavement. On the contrary, the pavement of most roads in Iran is of asphalt pavement type. Nowadays, in addition to economic and technical objectives, environmental aspects and sustainable development requirements are increasingly concerned in design, construction, and maintenance of pavements and the other infrastructural projects. The eco-friendly pavements (green pavements) are those in which environmental issues are concerned in all aspects (e.g., design, construction, and maintenance) [3].

Repetition of these stresses and tensions usually leads to pavement damage. In fact, fatigue cracks are craze cracks that increase with continuous loading in the pavement system and eventually expand in the form of cracks as a result of fatigue. Accumulation of these cracks finally results in pavement failure. Therefore, the prediction ability of pavement behaviour is remarkable against the fatigue phenomenon. Since the fatigue phenomenon almost occurred in the asphalt mixture, tests related to fatigue behaviour can be applied [4]. 
Fatigue refers to the phenomenon of failure due to load repetition, dynamic changes of the load, and its frequency, which may be even less than the final static resistance of asphalt. The resistance of the asphalt mixture to fatigue indicates the ability of the mixture against repetitive bending loads without failure in the asphalt mixture [5]. The accumulation of these cracks eventually leads to pavement rupture. These cracks are the main and fundamental failures in asphalt mixtures for medium temperatures, highlighting the importance of the ability to predict pavement behaviour against the fatigue phenomenon. Fatigue cracks can be classified into three groups of longitudinal cracks, transverse cracks, and alligator cracks.

Regarding the costly process of road pavement maintenance and the crucial role of road maintenance, it is necessary to provide solutions for improving the performance of pavement asphalt layers and increasing the life of the pavement $[4,5]$. In addition to the adverse effect on the pavement condition, the occurrence of various failures has an adverse effect on the accident frequency and can impose excessive costs on users of transportation infrastructure [2].

Nowadays, approaches such as asphalt mixture modification with nanomaterials or pavement layer reinforcement with geosynthetic materials have been highly used to increase the efficiency and resistance of mixtures to dynamic loads of vehicles, as well as to enhance resiliency against different environmental conditions.

The modification of asphalt binder used in asphalt mixtures is considered one of the efficient methods to achieve an asphalt mixture with higher resistance. With the advent of nanotechnology, researchers have also applied nanomaterials to improve the rheological properties of the asphalt binder and the performance of asphalt mixtures.

The results of experiments on bitumen indicate that nanosilica reduces the amount of viscosity at high temperatures and therefore differs from other nanoparticles. In general, nanosilica improves the rutting properties and cracks caused by fatigue of bitumen. In this way, adding nanosilica to pure bitumen slightly reduces the viscosity values of the modified bitumen. The low viscosity of bitumen leads to a decrease in the compaction temperature or, in other words, a reduction in energy consumption in the manufacturing process. Moreover, adding nanosilica to pure bitumen improves the recycling ability of the bitumen connection, improves the antiaging and cracking performance of the asphalt mixture modified with nanosilica significantly, and increases the abrasion resistance and resistance to the segregation of the asphalt mixture modified with nanosilica [6]. Based on the results, nanosilica has a positive effect on strain reversibility and leads to the maximum recovery for bitumen modified with $2 \%$ nanosilica [7].

Furthermore, the use of nanosilica in bitumen and asphalt mixtures increases the elasticity, reduces the phase angle, and enhances the complex modulus. Thus, the parameter $G^{*} \cdot \sin \delta$ is increased, which means a decrease in the fatigue resistance. To this aim, researchers suggested using ITS and linear amplitude sweep (LAS) tests for further analysis [8]. The fatigue life of bitumen modified with nanosilica is longer than that of titanium nanooxide and calcium noncarbonate such that adding $4 \%$ nanosilica to bitumen increases the fatigue life [9].

Furthermore, the results of other research studies illustrate the positive effect of nanosilica on fatigue life in 3 and $6 \mathrm{wt} \%$ (weight percent) of bitumen [10]. Nanosilica could increase the fatigue life, and its optimal value is equal to $7 \mathrm{wt} \%$ of bitumen [11]. It is worth noting that nanosilica can improve the thermal properties of hot asphalt mixtures to an acceptable level so that the use of this nanomaterial improves stiffness modulus of these mixtures and increases their resistance to applied loads due to the hardening of these mixtures [12]. On the contrary, researchers investigated the fatigue properties of an asphalt mixture modified with nanosilica after applying short-term aging conditions. By using indirect tensile strength testing equipment, the fatigue properties were investigated with different percentages of nanosilica from 2 to $6 \mathrm{wt} \%$. It was found that $4 \mathrm{wt} \%$ of nanosilica can increase the fatigue life of asphalt mixtures by up to $37 \%$, indicating the superior fatigue resistance of the specimen prepared with $4 \mathrm{wt} \%$ of nanosilica [13].

Geosynthetics are flat products made of polymeric materials and can be used as reinforcement in asphalt pavements to greatly increase their lifetime and prevent the formation of premature cracks. The efficiency of geosynthetics in asphalt pavements relies on many factors such as asphalt mixture, temperature, and location. Geogrids are among the common types of geosynthetics, which are recommended today to strengthen and improve the resistance of the asphalt layer, as well as to increase its useful life [14]. Regarding the growing trend of utilizing geogrids in recent years, the application of these materials can be considered as one of the best ways to improve the road, due to their simple implementation, delay in the spread of failure, and better economic efficiency [15].

In addition to reinforcing the asphalt layer and increasing the strength of shear and compressive stresses, geogrids have many pores and establish a good connection between the asphalt layers and the underlying layers, resulting in decreasing the damage rate of asphalt and increasing its lifespan [16]. Given the high tensile strength of geogrids, these materials can be used as reinforcing tools on roads [17]. The two main characteristics of these materials are high strength and negligible elongation, which result in an excellent performance of the geogrid between asphalt layers. Furthermore, the unit weight of asphalt geogrids is relatively low, leading to easy movement and better performance of the material.

Laurinavičius and Oginskas evaluated the causes of shear strain expansion and the rutting of asphalt pavements, as well as the main methods of deformation reduction. They indicated that the use of geogrids could improve the resistant properties of asphalt concrete [11]. Siriwardane et al. reinforced asphalt pavements by carrying out laboratory works using glass fiber grids. After conducting the necessary experiments on 20 laboratory specimens (control specimens and reinforced specimens) and performing numerical analyses, they studied the effect of using these reinforcement materials in asphalt mixtures. Based on the results, the use of glass fiber grids 
improved the performance of asphalt and enhanced the resistance to crack expansion [18].

Correia examined the benefits of using geogrids as reinforcement for asphalt mixtures and the impact of their application on the performance of flexible asphalt mixtures. Then, Correia investigated the tensile strain response of geogrids under traffic conditions. According to his findings, the use of geogrids reduced the expansion of strains at the bottom of asphalt layers, decreased vertical stresses in pavement substrates, and increased the resistance to rutting. Correia found that the utilization of geogrids not only delayed cracks but also improved the performance of flexible pavements [19]. Graziani et al. evaluated the effect of using reinforcements on the stress-strain response of asphalt pavements. Their laboratory work was performed on a part of the pavement reinforced by the glass fiber polymer grid (FP) and carbon fiber/glass fiber grid (CF) at the junction of two pavement layers. The results revealed a $65 \%$ reduction in strain in the asphalt section reinforced with CF, while no strain reduction was observed in the asphalt section reinforced with FP [20].

Shafabakhsh and Motamedi investigated the pavement reaction with and without geogrid reinforcement under various loads and at different speeds using ABAQUS finite element software, in addition to assessing the location of the geogrid at different depths. Based on the results, the location of the geogrid depends on the elasticity modulus of asphalt to the base and the thickness of the base. However, they showed that wheel speed and weight were ineffective in the mentioned results [15]. Lidia Sarah Calvarano et al. studied asphalt pavements reinforced with geogrids by conducting numerical studies using the three-dimensional finite element method (FEM-3D). The results of their numerical analyses indicated the effect of using glass fiber grids as reinforcement under suitable design conditions, as well as correct installation through improving the shear strength of the joint surface. In addition, it was found that the application of geogrids reduced the rutting caused by plastic deformation under repetitive traffic loads by about 57\% [21].

Correia et al. studied the creation and expansion of tensile strains along the geogrids reinforcing asphalt layers and showed that the presence of geogrids in the asphalt layer led to the creation of a lateral restraint mechanism, which could affect the mechanical behaviour of flexible pavements [22].

Shafabakhsh and Asadi evaluated the performance of geogrid- and sasobit-reinforced asphalt pavements in improving, maintaining, and creating reflective cracks. According to their results, loading conditions, temperature variation, and the sasobit percentage are important factors in the fatigue life of asphalt pavements. Besides, the simultaneous application of geogrid and sasobit improved the fatigue life and reduced crack propagation at all test temperatures and loading conditions, compared to the mixtures modified with only sasobit [23].

Ahmed evaluated the impact of using geogrid reinforcement between layers of asphalt concrete and concluded that the use of geogrids increased the life of asphalt concrete by almost three times [24]. By performing two-dimensional finite element simulations, Correia et al. examined the variables governing the performance of geogrid-reinforced pavement layers, as well as their effect on the response of flexible pavements. Their numerical predictions highlighted the significant effect of geogrids on the behaviour of pavement structures, especially pavements without a strong bed, by reducing displacement and vertical strains [25].

Nura Bala et al. addressed the functional properties of polypropylene polymer-modified bitumen with nanosilica particles in different percentages. In this research, the effect of nanosilica particles was examined by conducting bitumen functional tests, flexural four-point beam fatigue test, indirect tensile strength test, indirect tensile stiffness modulus test, and drain-down test. The results revealed that the addition of silica nanoparticles could improve the fatigue properties of bitumen modified with polypropylene polymer. Furthermore, the simultaneous application of thermoplastic polypropylene polymer with silica nanoparticles as bitumen modifiers enhanced the performance and durability of asphalt mixtures. Accordingly, the use of $2 \%$ nanosilica satisfies almost all functional properties [26].

Pasetto et al. studied the dynamic bending properties and shear strength of reinforced asphalt mixtures and showed the significantly increased reaction of reinforced asphalt layers against fatigue [27]. In another study, Ragni et al. used the accelerated pavement test (APT) and laboratory tests to examine the effect of using geocomposites on the formation of fatigue cracks, reflective cracks, and rutting. The results indicated that the use of geocomposites is an effective method to increase the performance of the asphalt pavement [28].

Ingrassia et al. investigated the formation of fatigue cracks, reflective cracks, and permanent deformations in thin asphalt pavements reinforced with geocomposites. According to their experimental results, the use of geocomposites could increase the service life of thin asphalts and reduce cracking and permanent deformations, in addition to increasing the amount of energy required to propagate cracks by three to eight times [29]. Consequently, Sudarsanan et al. predicted the fatigue life of asphalt by carrying out a four-point bending test using three types of geosynthetics at temperatures of 10,20 , and $30^{\circ} \mathrm{C}$. The improvement coefficients obtained from the results of their experiments showed that fatigue life increases from 1.2 to 12 times depending on the test temperature [30].

This research seeks to evaluate the simultaneous effect of using silica nanoparticles and geogrids on the fatigue life of asphalt mixtures and then compare the results with values related to asphalt specimens without any additives or reinforcement (control specimens), asphalt mixture specimens modified only with nanosilica (NSM-HMA specimens), and asphalt mixture specimens reinforced with geogrid (GRHMA specimens) at strain levels of 500, 700, and $900 \mu \varepsilon$. After introducing the modified-reinforced composite (MRC-HMA) mixture, the fatigue life of the mixture is compared with other previous models. For this purpose, the fatigue test of a 4-point bending beam was used to evaluate the fatigue life. 


\section{Methodology}

With regard to the aim of this paper, to determine the real effects of using the modified-reinforced composite (MRCHMA) mixture in increasing the fatigue life of the asphalt pavement, it has attempted to create four sets of asphalt slabs, which are the MRC-HMA specimen, specimen modified only with nanosilica (NSM-HMA), specimen reinforced only with geogrid (GR-HMA), and control specimen (that lacks any reinforcement/modifier).

By using a beam fatigue test apparatus, the repetitive bending loads are applied to the asphalt specimens, and then the mutual changes of the applied load and the created deformation are calculated. The test may be corrected under controlled stress or controlled strain at each load repetition to achieve the specified strain at the next iteration. In the controlled stress state, the applied force is assumed constant, and the deformation is also recorded. If bending occurs in the specimen, the maximum and minimum load levels are corrected to maintain the beam upright [31]. This section introduces materials (including aggregate, asphalt binder, nanosilica, and geogrid), specimens' preparation, and bitumen physical tests, as well as flexural fatigue theory and test procedure.

2.1. Materials. Figure 1 illustrates the granulation characteristics of the consumed aggregates in the granulation diagram. Furthermore, these materials are made up of siliceous rocks, the physical characteristics of which are presented in Table 1.

Bitumen used in this research has a penetration degree of 85-100. Table 2 presents the characteristics of the consumed bitumen control specimen and specimen modified with nanosilica. In this study, a set of tests was conducted to evaluate the effects of adding $5 \mathrm{wt} \%$ bitumen and nanosilica to the asphalt binder. Table 2 shows the results of these tests. As shown, the addition of nanosilica to the asphalt binder reduced the penetration degree and, at the same time, increased its softening degree compared to the pure bitumen state.

The additive used in this research is nanosilica, which is a product of the US company. The prepared nanosilica was mixed with $5 \mathrm{wt} \%$ bitumen for one hour at a temperature of $160^{\circ} \mathrm{C}$ and a speed of $4000 \mathrm{rpm}$. To prevent the nanomaterials from agglomeration and adhesion to the blades of the device, silica nanoparticles were added to the asphalt binder in stages. The extent and procedure of sample preparation were appropriate based on previous research [32-34]. The specifications are presented in Table 3.

The geogrids used in this research were made up of polypropylene with square meshes with a maximum width of $40 \mathrm{~mm}$. Geogrids were compatible with bitumen, and their application was in the reinforcement of the asphalt layer. Table 4 reports the specifications of geogrids used in this research.

2.2. Specimen Preparation. To conduct the experiments, asphalt beam specimens were made in four desired modes,

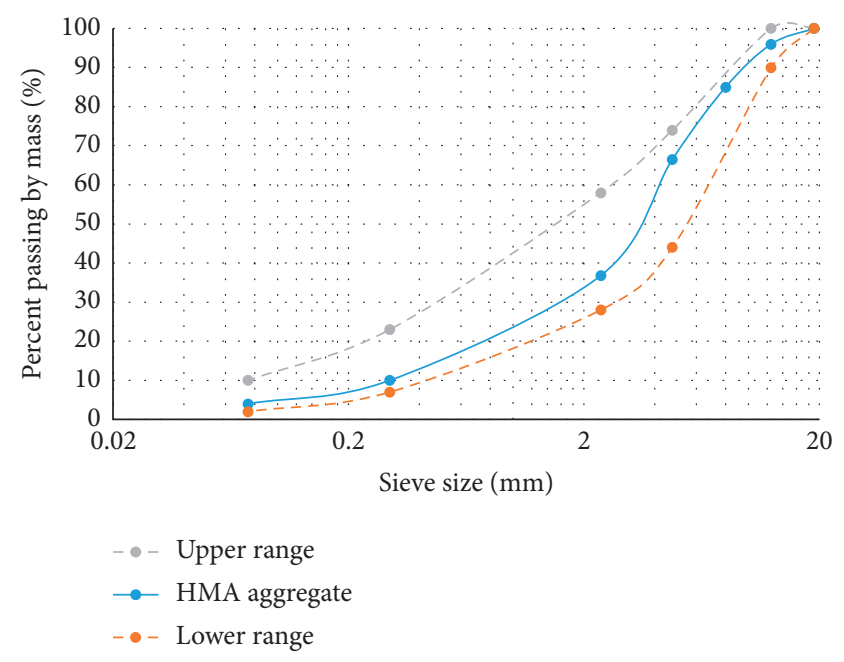

FIgURE 1: Granulation of consumable aggregate materials.

TABle 1: Physical characteristics of aggregates.

\begin{tabular}{lcc}
\hline Characteristics & Unit & Size \\
\hline Coarse aggregates & & \\
Weight loss against abrasion by the Los Angeles & $\%$ & 18 \\
method & $\%$ & 1.3 \\
Weight loss against sodium sulfate & $\%$ & 5 \\
Long seeds (elongation) & $\%$ & 17 \\
Wide seeds (flakiness) & $\%$ & 84 \\
Fracture in two sides on sieve no. 4 & $\mathrm{gr} / \mathrm{cm}^{3}$ & 2.527 \\
True specific gravity & $\mathrm{gr} / \mathrm{cm}^{3}$ & 2.665 \\
Bulk density & $\%$ & 2 \\
Water absorption & \multicolumn{2}{c}{} \\
Fine-grained aggregates & $\%$ & 7.1 \\
Weight loss against sodium sulfate & $\%$ & 72 \\
Sand equivalent & $\mathrm{gr} / \mathrm{cm}^{3}$ & 2.501 \\
True specific gravity & $\mathrm{gr} / \mathrm{cm}^{3}$ & 2.673 \\
Bulk density & $\%$ & 2.6 \\
Water absorption & \multicolumn{3}{c}{} \\
\hline Filler & $\mathrm{gr} / \mathrm{cm}^{3}$ & 2.680 \\
Specific weight & - & 8 \\
Plasticity index &
\end{tabular}

with a length of $380 \mathrm{~mm}$, a width of $50 \mathrm{~mm}$, and a height of $63 \mathrm{~mm}$, which are shown in Figure 2. The characteristics of these asphalt beams are as follows: control specimens without additives and reinforcement, GR-HMA specimens (the geogrid installation place is at the lower border of the one-third middle of the asphalt slab), specimens modified with 5\% nanosilica, and MRC-HMA specimens with 5\% nanosilica and geogrid.

To make the constructed specimens as close as possible to the natural and operational state, an asphalt slab was constructed in the asphalt factory area. In this way, aluminium foils were used to prevent the adhesion of the prepared slabs to the beneath layer, and then steel nails were applied to prevent displacement and shrinkage of the geogrid. Ultimately, the compaction process was performed with high accuracy to provide a uniform section. Concerning 
TABLE 2: Bitumen characteristics.

\begin{tabular}{lccc}
\hline Bitumen type & Penetration degree $(\mathrm{dmm})$ (ASTM D5) & Softening point $\left({ }^{\circ} \mathrm{C}\right)$ (ASTM D36) & Ductility (mm) (ASTM D113) \\
\hline Control specimen $(85-100)$ & 92.7 & 45.6 & $>100$ \\
Modified specimen $(85-100)$ & 65 & 56 & $>100$ \\
\hline
\end{tabular}

TABLE 3: Specifications of consumed nanosilica.

\begin{tabular}{lcccc}
\hline $\mathrm{SiO}_{2}$ & $\mathrm{Ti}$ & $\mathrm{Ca}$ & $\mathrm{Na}$ & $\mathrm{Fe}$ \\
\hline$>99 \%$ & $<120 \mathrm{ppm}$ & $<70 \mathrm{ppm}$ & $<50 \mathrm{ppm}$ & $<20 \mathrm{ppm}$ \\
\hline
\end{tabular}

TABLE 4: Specifications of used geogrids.

\begin{tabular}{|c|c|c|c|}
\hline Property & Standard & Unit & Value \\
\hline Pore size & - & $\mathrm{mm}$ & $40 \times 40$ \\
\hline Longitudinal/transverse tensile resistance & EN-ISO 10319 & $\mathrm{kN} / \mathrm{m}$ & 50.50 \\
\hline Elasticity at the maximum transverse/longitudinal force & EN-ISO 10319 & $\%$ & 11.23 \\
\hline Weight per unit area & EN 965 & $\mathrm{~g} / \mathrm{m}^{2}$ & 244 \\
\hline
\end{tabular}

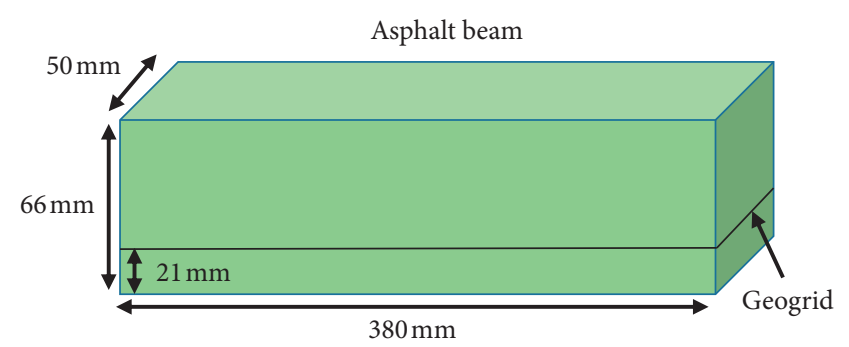

FIgUre 2: Dimensions of specimens made for testing GR-HMA and MRC-HMA specimens.

the construction of specimens where the geogrid was at the lower boundary of the middle one-third, the second layer was applied after the implementation of the first layer in the shortest possible time. To move the constructed section, the asphalt section was cut into smaller sizes after three days by the asphalt cutting machine to easily lift and move the asphalt section in the laboratory.

The prepared sections were transferred to the laboratory and cut using a special asphalt cutting machine according to the standard AASHTO T321, and the specimens were obtained with the final dimensions of $380 \mathrm{~mm} \times 63 \mathrm{~mm} \times 50 \mathrm{~mm}$.

\subsection{Flexural Fatigue Theory and Test Procedure}

2.3.1. Flexural Fatigue Theory. The flexural fatigue test of asphalt concrete beams is conducted according to the AASHTO T321 standard. The loading waveform is sinusoidal in a controlled stress state and sinusoidal and semisinusoidal in a controlled strain state. Under the controlled stress state, specified stress is applied until the failure stage of the specimen. However, the feedback system installed in the flexural fatigue test machine modifies the stress after each loading repetition so that the strain remains constant.
Under the controlled strain mode, the specimen can remain in the third stage for a long time without a significant decrease in the stiffness of the specimen due to the reduction in stress. For this reason, the failure criterion is generally defined as a reduction in stiffness to a percentage of initial stiffness. The standard AASHTO T321 sets this rate at $50 \%$. However, addressing the diagram of stiffness reduction versus load repetition is the best criterion for determining the failure limit of the specimen due to the differences in the calculation of initial stiffness and, sometimes, scattering in the results. According to another definition, the failure limit of the specimen is determined at the end of the second stage and the beginning of the third stage [31].

A pattern diagram indicating the stiffness versus load cycle changes, which can be divided into three sections in constant strain fatigue tests. This diagram is presented in Figure 3.

In the 1 st section, the drop rate of the hardness modulus is high. In the 2 nd section, the hardness drop-rate decreases, and in more loading cycles, this drop rate increases once more in the 3rd section, which indicates the deformation of fine cracks that have been created in asphalt mixtures and these small cracks joining each other. In the 3rd section, in which the rate of decrease of the hardness modulus increases once more, the growth rate of cracks increases, and large cracks develop. At the end of the 3rd section, total sample failure takes place.

Equations (1) to (4) present the functions used to calculate the output parameters of the beam fatigue test:

$$
\begin{aligned}
\sigma_{t} & =\frac{G_{0} P}{b h^{2}}, \\
\varepsilon_{t} & =\frac{12 h \delta \times 10^{6}}{3 G_{o}^{2}-4 G_{i}^{2}},
\end{aligned}
$$




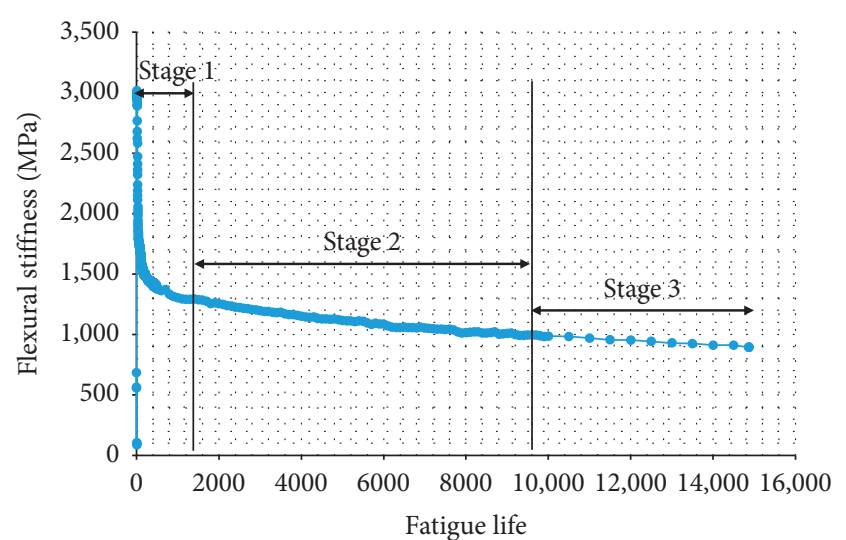

Figure 3: Pattern of change in hardness modulus versus loading cycle.

$$
\begin{aligned}
E_{s} & =\frac{1000 \times \sigma_{t}}{\varepsilon_{t}}, \\
E & =\left[\frac{P G_{i}}{\delta b h}\right] \times\left[\frac{3 G_{o}^{2}-4 G_{i}^{2}}{4 h^{2}+k(1+v)}\right],
\end{aligned}
$$

where $\sigma_{t}$ is the maximum tensile stress in $\mathrm{kPa}, P$ is the load applied to the specimen in $\mathrm{kN}, b$ is the the average specimen width in $\mathrm{mm}, h$ is the average specimen height in $\mathrm{mm}, G_{0}$ is the distance between supports $(355.5 \mathrm{~mm}), G_{i}$ is the distance between loading clamps $(118.5 \mathrm{~mm}), \varepsilon_{t}$ is the tensile strain, $\delta$ is the mean displacement in the middle of the beam in $\mathrm{mm}$, $E_{s}$ is the flexural stiffness in $\mathrm{mP}, E$ is the elasticity modulus in $\mathrm{mPa}, v$ is Poisson's ratio, and $k$ is the ratio of actual shear stress to average shear stress, which is assumed 1.5.

2.3.2. Conducting a Four-Point Bending Beam Fatigue Test. In general, at least three specimens are required to draw the fatigue curves for each of the four states, which were tested at three strain levels. In this experiment, the load was applied semisinusoidal with a frequency of $10 \mathrm{~Hz}$ and without rest in a controlled strain state. Moreover, the ambient temperature was maintained at about $20 \pm 0.8^{\circ} \mathrm{C}$.

Based on the results of previous research on the field of geosynthetics' application and to evaluate their potential in asphalt procedures, the specimens were tested at high strain surfaces. The desired strain levels include 500, 700, and $900 \mu \varepsilon$, and the experiments were continued until the failure stage (50\% reduction in the stiffness coefficient) against load repetition. Figure 4 depicts an example of a four-point bending beam fatigue test machine.

2.3.3. Modeling the Fatigue of the Asphalt Mixture. So far, numerous fatigue models have been introduced by researchers, some of which are the mechanistic-empirical model, Monismith model, shell model, Asphalt Institute model, Tayebali Model, PDMAP model, and Medani and Molenaar model [35, 36].

In this research, we used equation (5) which is one of the most common equations for modeling the fatigue life of

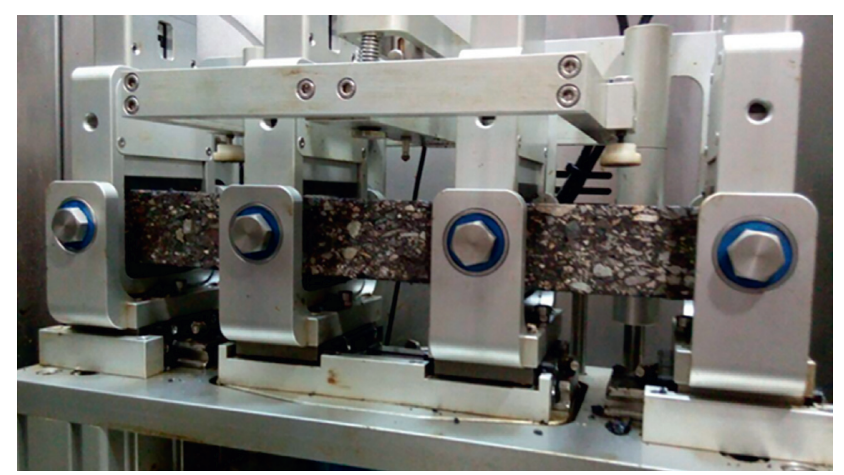

FIGURE 4: Four-point bending beam fatigue test machine.

asphalt mixtures. This relationship follows the structural form of the Medani and Molenaar model, in which the parameters $k$ and $n$ are calibrated according to the values of $N_{f}$ and $\varepsilon_{t}$ from the fatigue test results of the $4 \mathrm{~PB}$ bending beam [36].

$$
N_{f}=k\left(\frac{1}{\varepsilon}\right)^{n}
$$

where $N_{f}$ represents the fatigue life, $\varepsilon_{t}$ indicates the tensile strain, and $k$ and $n$ are laboratory regression coefficients.

2.3.4. Improvement Factor (IF) Parameter. The parameter IF means the number of loading cycles at the turning point of the permanent deformation diagram. This parameter is obtained under repetitive loads using the following equation:

$$
\mathrm{IF}=\frac{N_{f}^{\mathrm{th}}-N_{f}^{\text {control }}}{N_{f}^{\text {control }}},
$$

where $N_{f}^{\text {th }}$ demonstrates the number of load cycles to reach

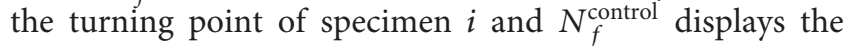
number of loading cycles to reach the turning point of the control specimen.

The higher the value of the IF parameter, the greater the ability of the asphalt mixture to delay crack propagation [37]. Besides, having a suitable mechanical interlocking between the asphalt layers minimizes the deformation at the failure point. The factors increasing the number of loading cycles up to the breaking point of the asphalt mixture include aggregate gradation, bitumen content, and use of modified bitumen. The use of modified bitumen significantly reduces crack growth in the pavement. Furthermore, modified bitumen decreases stress concentration at the crack tip and increases the number of loading cycles up to failure by deflecting the crack propagation path. The selection of an additive type for bitumen modification is regarded as one of the most important factors in preventing the expansion of cracks to the pavement surface [37].

\section{Results and Discussion}

3.1. Results of the Fatigue Test. In the $4 \mathrm{~PB}$ fatigue test by the fixed strain method, the fatigue life of the specimens was determined in three strain levels of 500, 700, and $900 \mu \varepsilon$ and 
for control asphalt concrete, GR-HMA, NSM-HMA, and MRC-HMA beams. In these tests, the number of repetitions was up to the failure stage, which is equivalent to a $50 \%$ reduction in stiffness. Figure 5 demonstrates the results obtained from the tests on the control specimens.

The use of nanosilica, as an additive to modify the physical and chemical behaviour of bitumen in this study, increased the fatigue resistance in the four-point bending test at all three levels of strain. As shown in Figure 5, it can be concluded that bitumen modified with nanosilica has significantly increased the tolerance of repetitive loads caused by the movement of vehicles, compared to the conventional state of pavements without nanosilica.

Based on the results which are shown in Figure 5, the use of geogrids in the asphalt pavement improves the properties of resistance to fatigue cracks, which can be attributed to the elasticity of these materials. Moreover, the results indicate that geogrids have a higher ability to deal with fatigue cracks, compared to the nanosilica additive.

Figure 5 also indicates the results of the test on the MRCHMA mixture. As shown, the combined use of nanosilica and geogrid in the asphalt mixture could significantly increase the fatigue life of asphalt against fatigue cracks.

As illustrated in Figure 5, the comparison and evaluation of asphalt mixtures against fatigue show the superiority of the simultaneous use of nanosilica and geogrids in asphalt mixtures. According to the objective observations during the beam fatigue tests, it was found that the GR-HMA specimens had better integrity and stability than those of the nonreinforced specimens after the end of the test, in addition to having a smaller width of the created cracks. The reason for this issue is that the geogrid layers remain almost intact at the end of the fatigue life of the GR-HMA specimens.

According to the preliminary calculations on the results which are displayed in Figure 5, if a reduction in stiffness by $50 \%$ of initial stiffness is the basis for the end of fatigue life, the fatigue life in GR-HMA specimens is, on average, up to twice that of control specimens, while it is increased by $72 \%$ in specimens containing nanosilica compared to nonreinforced specimens. However, the fatigue life is increased up to 6 times, on average, in GR-HMA and NSM-HMA specimens compared to the control ones.

3.2. Fatigue Life Prediction. Concerning the first step of processing the results, the fatigue life of different specimens was extracted, the results of which are described in Tables 5-7. The basis of fatigue life, which is used in subsequent analyses, is the reduction of stiffness to $50 \%$ of the initial stiffness. Next, the diagrams of strain levels versus fatigue life were plotted for all four states, and then, an exponential regression was performed on these points. Accordingly, the resulting graphs and equations, as well as their correlation coefficient $\left(R^{2}\right)[38,39]$, are presented in the following. The coefficients $k$ and $n$ are obtained based on equation (5), according to the contents of Tables 5-7. Tables 5-7 give the value of the IF factor for each state of specimens.

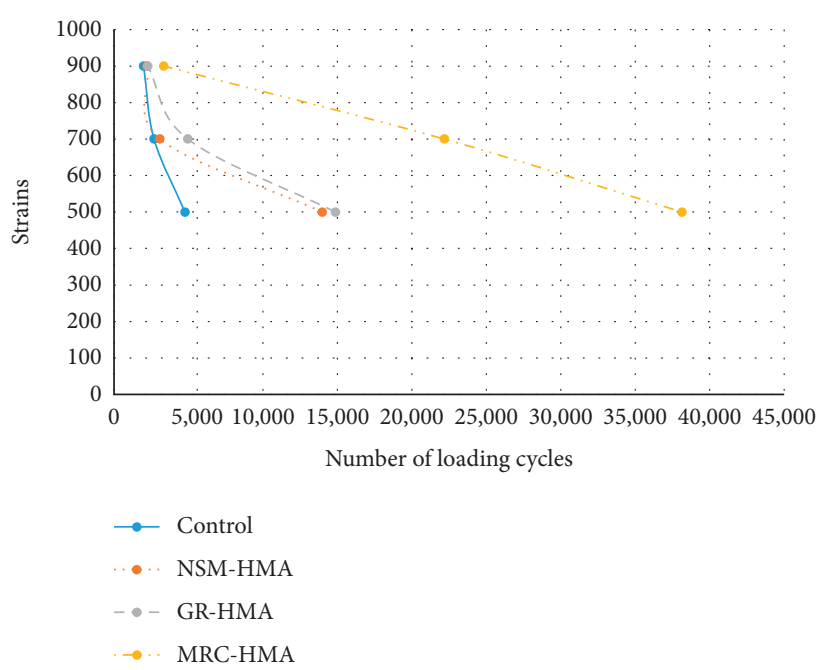

Figure 5: Comparison of the fatigue curves of control, NSM-HMA, GR-HMA, and MRC-HMA mixtures.

As mentioned in equation (5), the fatigue life equations are obtained by plotting the number of load repetitions against the initial tensile strain on a logarithmic scale and using the fitted line equation. It is noteworthy that the results of the tests are shown based on the same equation in this research (Table 8).

The values of $k$ obtained in Table 8 highlight that the effect of nanosilica and geogrids on increasing the fatigue life is more evident at high strain surfaces; this issue is noticeable in nanosilica. Furthermore, the values of $n$ indicate that the reduction rate of fatigue life is lower in specimens reinforced with geogrids than that of control specimens by increasing the stress level.

The correlation coefficient $R^{2}$ referred to equation (5) and explained the goodness of fit of the suggested functional form (equation (5)) with the fatigue data by considering the residual values. All the data were gathered from the original $4 \mathrm{~PB}$ fatigue tests, and the correlated equation was developed by common mathematical software. The high values of $R^{2}$ confirmed that the proposed functional form well fitted with gathered data and could predict the fatigue lives as fit as possible.

With regard to data in Tables 5 and 6 , it is observed that the NSM-HMA and GR-HMA specimens show better performance compared to the control samples, and the number of loading cycles until the failure stage is increased in these specimens.

The use of the asphalt binder modified with nanosilica in the asphalt mixture reduces the stress concentration at the crack tip, leading to the diversion of the crack propagation path and an increased number of cycles until the failure of modified asphalt.

Accordingly, it can be concluded that the performance of geogrids in asphalt specimens is mainly of reinforcing type, while the delay in the crack expansion is the factor that increases fatigue life in the specimens containing nanosilica. Generally, the use of geogrids increases the number of loading cycles and enhances the absorption of energy (crack 
TABLE 5: Ratio of the number of load repetitions in the asphalt mixture specimens modified with nanosilica to the control specimen.

\begin{tabular}{lccc}
\hline Strain level $(\mu \varepsilon)$ & Control sample (fatigue life) & NSM-HMA specimen (fatigue life) & IF \\
\hline 500 & 4760 & 13993 & 2.93 \\
700 & 2686 & 3080 & 1.14 \\
900 & 1987 & 2217 & 1.11 \\
\hline
\end{tabular}

TABLE 6: Ratio of the number of load repetitions in the GR-HMA mixture specimens to the control specimen.

\begin{tabular}{lccc}
\hline Strain level $(\mu \varepsilon)$ & Control sample (fatigue life) & GR-HMA specimen (fatigue life) & IF \\
\hline 500 & 4760 & 14873 & 3.12 \\
700 & 2686 & 4951 & 1.84 \\
900 & 1987 & 2257 & 1.13 \\
\hline
\end{tabular}

TABLE 7: Ratio of the number of load repetitions in the MRC-HMA mixture specimens to the control specimen.

\begin{tabular}{lccr}
\hline Strain level $(\mu \varepsilon)$ & Control sample (fatigue life) & MRC-HMA specimen (fatigue life) & IF \\
\hline 500 & 4760 & 38131 & 8.01 \\
700 & 2686 & 22169 & 8.25 \\
900 & 1987 & 3337 & 1.67 \\
\hline
\end{tabular}

TABLE 8: Fatigue equations' parameters.

\begin{tabular}{lccc}
\hline Asphalt specimen & Coefficient $k$ & Coefficient $n$ & Correlation coefficient $R^{2}$ \\
\hline Control & $8.0751 \times 10^{11}$ & 0.651 & 0.9621 \\
NSM-HMA & $7.5095 \times 10^{12}$ & 0.751 & 0.9854 \\
GR-HMA & $5.1761 \times 10^{10}$ & 0.690 & 0.9827 \\
MRC-HMA & $6.1881 \times 10^{12}$ & 0.750 & 0.9800 \\
\hline
\end{tabular}

formation energy), compared to the nanosilica modifier. Evaluating the results of GR-HMA and NSM-HMA specimens revealed a slight difference in the capability of these two solutions in increasing the fatigue life of asphalt mixtures. However, reviewing the results of the MRC-HMA specimen indicated that the simultaneous use of modifiers and reinforcements in the asphalt mixture has a significant effect on the fatigue behaviour of the asphalt mixture. Therefore, the use of the MRC-HMA mixture can be a desirable and acceptable option for pavements that are exposed to heavy or frequent traffic loads so that this type of mixture can increase the fatigue life by more than 2.5 times at the strain level of $500 \mu \mathrm{s}$ compared to other reinforced specimens. Nevertheless, an increase in the fatigue life is not significant at the strain level of $900 \mu \varepsilon$ and is increased by about $50 \%$ compared to other reinforced specimens.

The main reason of increasing the fatigue life of MRCHMA could be referred to the combo effect of reinforcement and modification of the asphalt mixture. By adding nanosilica to the HMA mixture, the resistance of the asphalt mixture to fatigue cracking increases due to the high specific area of the nanosilica additive. In fact, by being in the binder structure, nanosilica changes the rheology of the binder, reinforces its network, and at last, increases the resistance of the asphalt mixture to repetitive loads (as shown in IF values of Table 5). So, the presence of nanosilica causes binder hardening, enhances the asphalt resilient modulus, and raises the fatigue life of NSM-HMA mixtures.
On the contrary, the presence of reinforcement in the pavement creates membrane effect and lateral restraint mechanism, which could affect the mechanical behaviour of flexible pavements. In fact, the normal stresses are dispread and dissipated laterally along the geogrid reinforcement (as shown in IF values of Table 6).

Explaining the priority of the MRC-HMA reaction to the cyclic loads is very complicated. The first reaction could be referred to the nanosilica modifier, in which it helps to absorb the stresses and control the strains up to the time, and the reinforcement element reacts as a stress relief component, although the interaction between the reinforcement and the modified mixture could not be solely considered (as shown in IF values of Table 7).

\section{Conclusions}

This research sought to introduce MRC-HMA and evaluate its performance in increasing the fatigue life. For this purpose, the fatigue life of the composite mixture was compared with the control specimen (the asphalt mixture without any additives or reinforcement), the specimen modified with 5\% nanosilica (NSM-HMA), and the specimen reinforced with geogrids (GR-HMA). Some of the results of this study are as follows.

The use of GR-HMA specimens has almost the same results as NSM-HMA specimens such that the GR-HMA specimen can increase the fatigue life by about $20 \%$ at the 
strain level of $500 \mu \varepsilon$. The main reason for the more desirable fatigue behaviour of the GR-HMA specimen may be due to the reinforcing performance of the geogrid, which can increase the fatigue life of the mixture to some extent by absorbing the stresses from the traffic load.

Despite better fatigue behaviour of the GR-HMA specimens relative to the NSM-HMA specimens, this difference may not be large enough to be required by the designer. However, the use of the MRC-HMA mixture can significantly increase the fatigue life of the asphalt mixture. Thus, this mixture can be a good option for pavements that are exposed to heavy or light (with a large number) traffic loads, which usually have a significant adverse effect on the fatigue behaviour of asphalt mixtures.

Based on the results, the IF values for the MRC-HMA specimen and simultaneously NSM-HMA for the strain levels of 500,700 , and $900 \mu \varepsilon$ are equal to $2.73,7.23$, and 1.5 compared to the NSM-HMA specimens, respectively. Similarly, the IF values for the MRC-HMA specimen and simultaneously GR-HMA for the strain levels of 500, 700, and $900 \mu \varepsilon$ are equal to $2.56,4.48$, and 1.47 , compared to the GR-HMA specimens, respectively.

Some of the other quantitative improvements due to the addition of reinforcement and modifier are discussed as follows:

The MRC-HMA mixtures increased the fatigue life at strain levels of 500,700 , and $900 \mu \varepsilon$ to up to about 701 , 725.3 , and $67.9 \%$, respectively, compared to the control specimens

The MRC-HMA mixtures increased the fatigue life at strain levels of 500,700, and $900 \mu \varepsilon$ to up to about 172.5 , 619.77, and 50.51, respectively, compared to NSMHMA mixtures

The MRC-HMA mixtures increased the fatigue life at strain levels of 500,700 , and $900 \mu \varepsilon$ to up to about $156.37,347.76$, and $47.85 \%$, respectively, compared to GR-HMA mixtures

\section{Data Availability}

Access to data is restricted, except the revealed data in the manuscript. Some or all data are available from the corresponding author upon request.

\section{Conflicts of Interest}

The authors declare that they have no conflicts of interest.

\section{References}

[1] M. Akbari, G. A. Shafabakhsh, and M. R. Ahadi, "Evaluating the safety effects of pavement condition index (PCI) on frequency of run-off-road accidents," Journal of Transportation Infrastructure Geotechnology, vol. 1, no. 3, pp. 47-61, 2015.

[2] M. Akbari, G. Shafabakhsh, and M. R. Ahadi, "Single-vehicle run-off-road crash prediction model associated with pavement characteristics," International Journal of Engineering, vol. 33, no. 7, pp. 1375-1386, 2020.
[3] T. Wang, F. Xiao, X. Zhu, B. Huang, J. Wang, and S. Amirkhanian, "Energy consumption and environmental impact of rubberized asphalt pavement," Journal of Cleaner Production, vol. 180, pp. 139-158, 2018.

[4] Y. Huang, R. N. Bird, and O. Heidrich, "A review of the use of recycled solid waste materials in asphalt pavements," Resources, Conservation and Recycling, vol. 52, no. 1, pp. 58-73, 2007.

[5] L. Sun, Structural Behavior of Asphalt Pavements, Butterworth-Heinemann, Elsevier, Amsterdam, Netherlands, 2016.

[6] F. Zafari, M. Rahi, N. Moshtagh, and H. Nazockdast, "The improvement of bitumen properties by adding nano silica," Third International Conference on Advances in Civil, Structural and Construction Engineering, vol. 3, pp. 62-69, 2014.

[7] H. Yao, Z. You, L. Li et al., "Rheological properties and chemical bonding of asphalt modified with nanosilica," Journal of Materials in Civil Engineering, vol. 25, no. 11, pp. 1619-1630, 2013.

[8] G. H. Hamedi, F. M. Nejad, and K. Oveisi, "Estimating the moisture damage of asphalt mixture modified with nano zinc oxide," Materials and Structures, vol. 49, no. 4, pp. 1165-1174, 2016.

[9] H. Nazari, K. Naderi, and F. Moghadas Nejad, "Improving aging resistance and fatigue performance of asphalt binders using inorganic nanoparticles," Construction and Building Materials, vol. 170, pp. 591-602, 2018.

[10] M. Adamu, B. Mohammed, and N. Shafiq, "Nano silica modified roller compacted rubbercrete-an overview," Civil, Offshore and Environmental Engineering, vol. 2016, pp. 483487, 2016.

[11] A. Laurinavičius and R. Oginskas, "Experimental research on the development of rutting in asphalt concrete pavements reinforced with geosynthetic materials," Journal of Civil Engineering and Management, vol. 12, no. 4, pp. 311-317, 2006.

[12] M. Firouzinia and G. Shafabakhsh, "Investigation of the effect of nano-silica on thermal sensitivity of HMA using artificial neural network," Construction and Building Materials, vol. 170, pp. 527-536, 2018.

[13] M. Faramarzi, M. Arabani, A. K. Haghi, and V. Mottaghitalab, "Carbon nanotubes-modified asphalt binder: preparation and characterization," International Journal of Pavement Research and Technology, vol. 8, no. 1, pp. 29-37, 2015.

[14] I. L. Al-Qadi, S. H. Dessouky, J. Kwon, and E. Tutumluer, "Geogrid in flexible pavements," Transportation Research Record: Journal of the Transportation Research Board, vol. 2045, no. 1, pp. 102-109, 2008.

[15] G. A. Shafabakhsh and M. Motamedi, "Sensitivity analysis of road actual conditions to evaluate the optimal positioning of geogrid using finite elements and dynamic methods," International Journal of Engineering, vol. 29, no. 9, pp. 1235-1241, 2016.

[16] R. Hass, J. Walls, and R. G. Carroll, "Geogrid reinforcement of granular bases in flexible pavements," Transportation Research Record: SAGE Journals, vol. 1188, pp. 19-27, 1988.

[17] A. Zofka and M. Maliszewski, "Practical overlay design method for geogrid reinforcement of asphalt layers," Road Materials and Pavement Design, vol. 20, no. sup1, pp. S163S182, 2019.

[18] H. Siriwardane, R. Gondle, and B. Kutuk, "Analysis of flexible pavements reinforced with geogrids," Geotechnical and Geological Engineering, vol. 28, no. 3, pp. 287-297, 2010.

[19] N. D. S. Correia, Performance of flexible pavements enhanced using geogrid-reinforced asphalt overlays, Ph.D. thesis, Universidade Federal de São Carlos, Sao Paulo, Brazil, 2014.

[20] A. Graziani, E. Pasquini, G. Ferrotti, A. Virgili, and F. Canestrari, "Structural response of grid-reinforced 
bituminous pavements," Materials and Structures, vol. 47, no. 8, pp. 1391-1408, 2014.

[21] L. S. Calvarano, R. Palamara, G. Leonardi, and N. Moraci, "3D-FEM analysis on geogrid reinforced flexible pavement roads," IOP Conference Series: Earth and Environmental Science, vol. 95, no. 2, 2017.

[22] N. S. Correia and J. G. Zornberg, "Strain distribution along geogrid-reinforced asphalt overlays under traffic loading," Geotextiles and Geomembranes, vol. 46, no. 1, pp. 111-120, 2018.

[23] G. Shafabakhsh and S. Asadi, "Investigating the effect of AC overlays reinforced with geogrid and modified by sasobit on rehabilitation of reflective cracking," Journal of Rehabilitation in Civil Engineering, vol. 8, no. 1, pp. 133-148, 2020.

[24] M. Ahmed, "Geogrid reinforcement in flexible paved roads," in Proceedings of the 12th International Transportation Specialty Conference, pp. 104-113, Fredericton, Canada, 2018.

[25] N. S. Correia, E. R. Esquivel, and J. G. Zornberg, "Finiteelement evaluations of geogrid-reinforced asphalt overlays over flexible pavements," Journal of Transportation Engineering, Part B: Pavements, vol. 144, no. 2, Article ID 04018020, 2018.

[26] N. Bala, M. Napiah, and I. Kamaruddin, "Effect of nanosilica particles on polypropylene polymer modified asphalt mixture performance," Case Studies in Construction Materials, vol. 8, pp. 447-454, 2018.

[27] M. Pasetto, E. Pasquini, G. Giacomello, and A. Baliello, "Innovative composite materials as reinforcing interlayer systems for asphalt pavements: an experimental study," Road Materials and Pavement Design, vol. 20, no. sup2, pp. S617S631, 2019.

[28] D. Ragni, T. Montillo, A. Marradi, and F. Canestrari, "Fast falling weight Accelerated pavement testing and laboratory analysis of asphalt pavements reinforced with geocomposites," in Proceedings of the 5th International Symposium on Asphalt Pavements \& Environment (APE), 219AD, pp. 417-430, Padua, Italy, 2018.

[29] L. P. Ingrassia, A. Virgili, and F. Canestrari, "Effect of geocomposite reinforcement on the performance of thin asphalt pavements: accelerated pavement testing and laboratory analysis," Case Studies in Construction Materials, vol. 12, Article ID e00342, 2020.

[30] N. Sudarsanan, A. Arulrajah, R. Karpurapu, and V. Amrithalingam, "Fatigue performance of geosyntheticreinforced asphalt concrete beams," Journal of Materials in Civil Engineering, vol. 32, no. 8, Article ID 04020206, 2020.

[31] AASHTO T321, "Standard method of test for determining the fatigue life of compacted asphalt mixtures subjected to repeated flexural bending," American Association of State Highway and Transportation Officials, vol. 7, pp. 1-11, 2011.

[32] S. Lu, X. Xian-tao, and Y. Peng, "Pavement performance of nano- $\mathrm{SiO}_{2}$ modified asphalt mixture," Journal of Highway and Transportation Research and Development, vol. 30, pp. 1-5, 2013.

[33] M. Hasaninia and F. Haddadi, "The characteristics of hot mixed asphalt modified by nanosilica," Petroleum Science and Technology, vol. 35, no. 4, pp. 351-359, 2017.

[34] J. Yang and S. Tighe, "A review of advances of nanotechnology in asphalt mixtures," Procedia-Social and Behavioral Sciences, vol. 96, pp. 1269-1276, 2013.

[35] L. Wang, Mechanics of Asphalt: Microstructure and Micromechanics, McGraw-Hill Education, New York, NY, USA, 1st edition, 2010.
[36] I. S. Bessa, Laboratory and field study of fatigue cracking prediction in asphalt pavements, Ph.D. thesis, Universidade Federal de São Carlos, Sao Paulo, Brazil, 2017.

[37] G. Shafabakhsh and S. Ahmadi, "Reflective cracking reduction by a comparison between modifying asphalt overlay and sand asphalt interlayer: an experimental evaluation," International Journal of Pavement Engineering, pp. 1-9, 2019.

[38] M. Akbari, G. Shafabakhsh, and M. R. Ahadi, "The impact of segmentation method on the aggregate goodness-of-fit measurements of non-linear crash prediction models," SN Applied Sciences, vol. 2, no. 10, 2020.

[39] H. Ghazvinian, H. Bahrami, H. Ghazvinian, and S. Heddam, "Simulation of monthly precipitation in semnan city using ANN artificial Intelligence model," Journal of Soft Computing in Civil Engineering, vol. 4, no. 4, pp. 36-46, 2020. 